\title{
Statistical analysis of indoor parameters an subjective responses of building occupants in a hot region of Indian ocean; a case of Madagascar island
}

\author{
Modeste Kameni Nematchoua $^{\mathrm{a}, \mathrm{b}, *}$, Paola Ricciardi ${ }^{\mathrm{a}}$, Cinzia Buratti ${ }^{\mathrm{c}}$ \\ a Department of Civil Engineering and Architecture, University of Pavia, Via Ferrata 1, 27100 Pavia, Italy \\ b Fluid and Energy Laboratory, Higher Polytechnic School, University of Antsiranana, Madagascar \\ ${ }^{c}$ Department of Engineering, University of Perugia, Via G. Duranti 63, 06125 Perugia, Italy
}

\section{H I G H L I G H T S}

- The $80 \%$ of voters found their environment comfortable.

- In all the studied places, during both seasons, no people voted "cold environment".

- The $52.0 \%$ of male were satisfied of their thermal environment.

- An ANOVA analysis shown that the voters are feeling more comfortable in hospitals.

- No great differences between males and females in their thermal sensations.

\section{A R T I C L E I N F O}

\section{Keywords:}

Statistical analysis

Indoor parameters

Subjective responses

Building occupants

Madagascar island

\begin{abstract}
A B S T R A C T
The present research reports the results of a questionnaire-based statistical study of some complex parameters derived from subjective answers by occupants regarding thermal comfort in their area of residence. There is not enough data regarding comfort in residential environment in Madagascar. This will help to define guidelines for constructing more comfortable buildings in Madagascar and other countries on the Indian Ocean. The experimental field study was carried out in 5 big hospitals, 50 small and big shopping centers, 67 traditional buildings, and 25 schools, which were distributed in 25 districts with different micro-climates of the urban communes in Northern of Madagascar. A total of 1092 people were investigated by means of 250 interviews and 842 analysed questionnaires during rainy and dry seasons. The physical measurements of air temperature and other parameters were performed simultaneously. Results showed that there were no very great differences between males and females thermal sensations, humidity sensations, and air movement sensations. The air temperature and relative humidity have a significant impact on the thermal preference in the studied place. With air temperature between 22.9 and $27.2^{\circ} \mathrm{C}$, relative humidity from 45.2 to $70.5 \%$, associated with air speed varying from 0.15 to $0.45 \mathrm{~m} / \mathrm{s}$, at least $80 \%$ of voters found their environment comfortable.
\end{abstract}

\section{Introduction}

Statistical analysis of subjective responses of occupants regarding the thermal comfort in their habitat is very important, because the results can allow the modelling of building design. Natural ventilation is an important sustainable building design strategy which is known to mankind for centuries $[1,2]$. In some studies, it is recommended to improve indoor air for buildings natural ventilation $[3,4]$, and according to other research, the energy consumption in building can be minimized, also by exploiting natural ventilation [5-8]. Some authors showed that the effective distribution of fresh air within an occupied space is of considerable importance in ensuring thermal comfort and good indoor air quality $[9,10]$. In a study of thermal comfort, personal parameters are more difficult to estimate or measure and, therefore, are usually assumed to be constant default values for a group of people. But in buildings, it was noticed that the real occupancy pattern of occupants may significantly differ from each other [11]. The methods adopted by researchers to study thermal comfort in buildings in the last years have been initiated under Fanger's foundation, but at the moment, an adaptive approach was encouraged by numerous standard norms. A number of empirical and numerical researchs were carried out to investigate the thermal comfort in several occupants' places [12-19]. In shopping centers, Hong Jin et al. [20] showed that the existence of daylighting plays an important role in subjective satisfaction, but not

\footnotetext{
* Corresponding author at: Department of Civil Engineering and Architecture, University of Pavia, Via Ferrata 1, 27100 Pavia, Italy. Tel.: +261322430984

E-mail address: kameni.modeste@yahoo.fr (M.K. Nematchoua).
} 
Table 1

Some climatic characteristics of Antsiranana city (yearly data).

\begin{tabular}{|c|c|c|c|c|c|c|c|c|c|c|c|}
\hline \multirow[b]{2}{*}{ City } & \multirow[b]{2}{*}{ Latitude } & \multirow[b]{2}{*}{ Longitude } & \multirow[b]{2}{*}{ Altitude (m) } & \multicolumn{2}{|c|}{ Temp. $\left({ }^{\circ} \mathrm{C}\right)$} & \multicolumn{2}{|c|}{ RH (\%) } & \multicolumn{2}{|c|}{ Wind speed (m/s) } & \multicolumn{2}{|c|}{ Precipitation (mm/year) } \\
\hline & & & & Max. & Min. & Max & Min. & $\operatorname{Max}$ & Min & $\operatorname{Max}$ & Min \\
\hline Antsiranana & $12^{\circ} 16^{\prime} \mathrm{S}$ & $49^{\circ} 17^{\prime} \mathrm{E}$ & 43.0 & 33.5 & 20.0 & 85.5 & 60.5 & 9.0 & 4.5 & 338.0 & 0.0 \\
\hline
\end{tabular}

Table 2

Periods of study.

\begin{tabular}{llllllll}
\hline & \multicolumn{2}{l}{ Dry season } & & \multicolumn{2}{l}{ Rainy season } \\
\cline { 2 - 3 } \cline { 6 - 8 } City: Antsiranana & Time & Month & Year & & Time & Month & Year \\
\hline Kind of building & & & & & & \\
Traditional habitat & 14 days & June & 2016 & & 7 days & December & 2016 \\
School & 14 days & September & 2016 & & 6 days & November & 2016 \\
Hospital & 10 days & September & 2016 & & 8 days & December & 2016 \\
Shopping center & 13 days & July & 2016 & & 10 days & December & 2016
\end{tabular}

crucial enough to their brightness perception. Belleri and Avantagiato [21] showed that the typical architectural archetypes of shopping centers such as atria and galleries revealed to be suitable for the integration of natural ventilation strategies. Montella [22] showed that inside a mall, the free running configuration is able to provide comfortable values also in the most critical climatic conditions. Craig and de Dear [23] showed that in shopping centers, a key behavioural mechanism that attenuates thermal discomfort indoors is the adjustment of clothing insulation levels. In hospitals in Malaysia, Fatemeh el al. [24] found that during the day time patient ward is "slightly cool" to "cool" and during night time it is "cold". The research carried out by Jamal and Nazanin [25] concluded that it is important to find some solutions to reconcile the different thermal comfort conditions required by different occupants in hospitals. The results of chi-square tests carried out by Ruey-Lung et al. [26] revealed that patients'physical strength significantly affected their thermal requirements. Jamal and Ian Knigh [27] concluded that is possible to reconcile different needs when the occupants of hospitals require widely varying thermal conditions to achieve thermal comfort. Melhado et al. [28] showed that evaluating the "thermal risks" of the patient is very important in order to know how to prevent him/her from suffering hypothermia. Other studies in hospitals are focused on thermal comfort in operating rooms, in ward areas and with reference to [29-32], On the other hand, in schools, the research of Kameni et al. [33] suggested that the increase in air velocity in schools is an essential phenomenon for obtaining thermal comfort. Teh et al. [34] in a UK primary school, suggested that children have a different thermal perception than adults. Jullivon and Trujillo [35] showed that when the temperature is barely outside of the comfort zone, a significant portion of the classroom feels uncomfortable. Kamaruzzaman et al. [36] showed that the environmental condition of a class can be warm and hot in 7-point ASHRAE scale. Finally, in traditional buildings, some research were raported in [37-44]. In the present paper the thermal comfort in Madagascar is studied. Madagascar is a big island in where are present five islands; the Comoros, Madagascar, Mauritius, Reunion, and the Seychelles. The closest ones are $200 \mathrm{~km}$ apart, the furthest ones are $1800 \mathrm{~km}$ apart. No investigations about thermal comfort have been yet carried out in regularly-occupied buildings like shopping centers, hospitals, traditional buildings, and schools in tropical climates of India Ocean. The choice of Madagascar as the place for this study was not made randomly. It is the biggest island of Indian Ocean and the 4th in the world. Madagascar, according to World Meteorological Organization, is considered as the third-ranking country in the world that is most vulnerable to climate change and this change affects indoor air in buildings. The Madagascar fragility in the face of multiple climates and crossing cyclone, motivates the population of northern Madagascar to build with temporary and cheap materials on the market.

The overall purpose of this research is to make a statistical analysis of some complex parameters coming from subjective responses of building occupants and physical measures in order to finally suggest the development of a standard norm more suitable for this country. Results could help building designers to be more efficient and to help all the regions with same climate to expand their database.

\section{Materials and methods}

\subsection{The studied region}

Located in the $20^{\circ} 00$ latitude South and in the $47^{\circ} 00$ longitude East, Madagascar lies almost entirely within the tropical region. It is an island in the Indian Ocean, covering an area of $592.000 \mathrm{~km}^{2}$. It is the fourth greatest island in the world, and it is separated from Africa by the Mozambique Channel by about $400 \mathrm{~km}$. There are basically two seasons in Madagascar: dry, from May to October, and rainy, from November to April. Two short seasons of approximately 1-month duration separate these two seasons. From May to October, the climate is conditioned by an anticyclone to the Indian Ocean level, that directs a wind regime of trade winds South-East on Madagascar. During this season, the eastern part of the island experiences a humid climate "in the wind", while the western part undergoes a drought-like climate termed "down wind". The study was conducted in the tropical city of Antsiranana (Northern region).

Antsiranana is the largest city in northern Madagascar. It is the capital of the province of Diego-Suarez. Its population was estimated at 257,163 inhabitants in 2014. The town of Antsiranana is sheltered by the bay of Diego-Suarez (156 km of coast) which shelters the second

Table 3

Characteristics of the measurement system.

\begin{tabular}{|c|c|c|c|c|}
\hline EMC 50081-1 (model) & Function & Range & Resolution & Accuracy \\
\hline \multicolumn{5}{|l|}{ Infrared thermometer } \\
\hline & Temperature & -50 to $+1000{ }^{\circ} \mathrm{C}$ & $0.1^{\circ} \mathrm{C}$ & $\pm 1.5 \% \mathrm{R} \pm 0.2^{\circ} \mathrm{C}$ \\
\hline \multicolumn{5}{|l|}{ Thermohygrometer } \\
\hline & Temperature & $0-50{ }^{\circ} \mathrm{C}$ & $0.1^{\circ} \mathrm{C}$ & $\pm 0.5{ }^{\circ} \mathrm{C}$ \\
\hline & Humidity & $0.1-99.9 \%$ & $0.1 \%$ & $\pm 3 \%(10-90 \%)$ \\
\hline \multirow{2}{*}{\multicolumn{5}{|c|}{$\begin{array}{l}\text { Anemometer } \\
\text { Model:DA01 }\end{array}$}} \\
\hline & & & & \\
\hline & Wind speed & $0-30 \mathrm{~m} / \mathrm{s}$ & $0.1 \mathrm{~m} / \mathrm{s}$ & $\pm 5 \%$ \\
\hline & Temperature & -10 to $45^{\circ} \mathrm{C}$ & $0.2^{\circ} \mathrm{C}$ & $\pm 2{ }^{\circ} \mathrm{C}$ \\
\hline
\end{tabular}


Table 4

Characteristics of the voters (results of interviews and questionnaires).

\begin{tabular}{|c|c|c|c|c|c|c|c|c|c|c|c|c|c|c|c|c|c|c|}
\hline & \multicolumn{3}{|c|}{ Occupants } & \multicolumn{3}{|c|}{ Height (m) } & \multicolumn{3}{|c|}{ Weight (kg) } & \multicolumn{3}{|c|}{$\mathrm{I}_{\mathrm{cl}}(\mathrm{Clo})$} & \multicolumn{3}{|c|}{ M (met) } & \multicolumn{3}{|l|}{ Age } \\
\hline & $\mathrm{M}$ & $\mathrm{F}$ & $\mathrm{T}$ & Min & Med & $\operatorname{Max}$ & Min & Med & Max & Min & Med & Max & Min & Med & $\operatorname{Max}$ & Min & Med & Max \\
\hline Trad.build. & 37 & 30 & 67 & 1.41 & 1.59 & 1.65 & 55.00 & 60.50 & 95.00 & 0.50 & 0.92 & 1.50 & 1.00 & 1.10 & 1.20 & 18 & 38 & 64 \\
\hline Schools & 250 & 375 & 625 & 1.55 & 1.65 & 1.89 & 35.00 & 59.00 & 79.00 & 0.40 & 0.86 & 1.45 & 1.00 & 1.00 & 1.10 & 14 & 18 & 25 \\
\hline Shopping & 80 & 22 & 102 & 1.55 & 1.69 & 1.80 & 35.00 & 71.00 & 90.00 & 0.40 & 0.92 & 1.50 & 1.00 & 1.10 & 1.20 & 23 & 30 & 50 \\
\hline Hospital & 144 & 154 & 298 & 1.55 & 1.68 & 1.78 & 33.00 & 61.00 & 90.00 & 0.70 & 0.85 & 1.40 & 1.00 & 1.00 & 1.10 & 13 & 45 & 89 \\
\hline Total/mean & 511 & 581 & 1092 & 1.41 & 1.65 & 1.89 & 33.00 & 62.9 & 95.00 & 0.40 & 0.88 & 1.50 & 1.00 & 1.00 & 1.20 & 13 & 33 & 89 \\
\hline
\end{tabular}

Table 5

Adopted thermal scale.

\begin{tabular}{|c|c|c|c|c|c|}
\hline Thermal sensation & Humidity sensation & Air movement sensation & Thermal satisfaction & Thermal preference & Thermal comfort \\
\hline-3 cold & -3 too dry & -3 no wind & -2 dissatisfied & -2 cooler & -2 very uncomfort. \\
\hline-2 cool & -2 dry & -2 only little wind & -1 slightly dissatisfied & -1 slightly cooler & -1 uncomfortable \\
\hline-1 Slightly cool & -1 Slightly dry & -1 wind not enough & 0 satisfied & 0 no change & 0 comfortable \\
\hline 0 neutral & 0 neutral & 0 just right & +1 slightly satisfied & +1 slightly warmer & +1 very comfort. \\
\hline + 1 Slightly warm & +1 slightly humid & +1 slightly breezy & +2 very satisfied & +2 warmer & \\
\hline+2 warm & +2 humid & +2 too breezy & & & \\
\hline+3 hot & +3 too humid & +3 much too breezy & & & \\
\hline
\end{tabular}
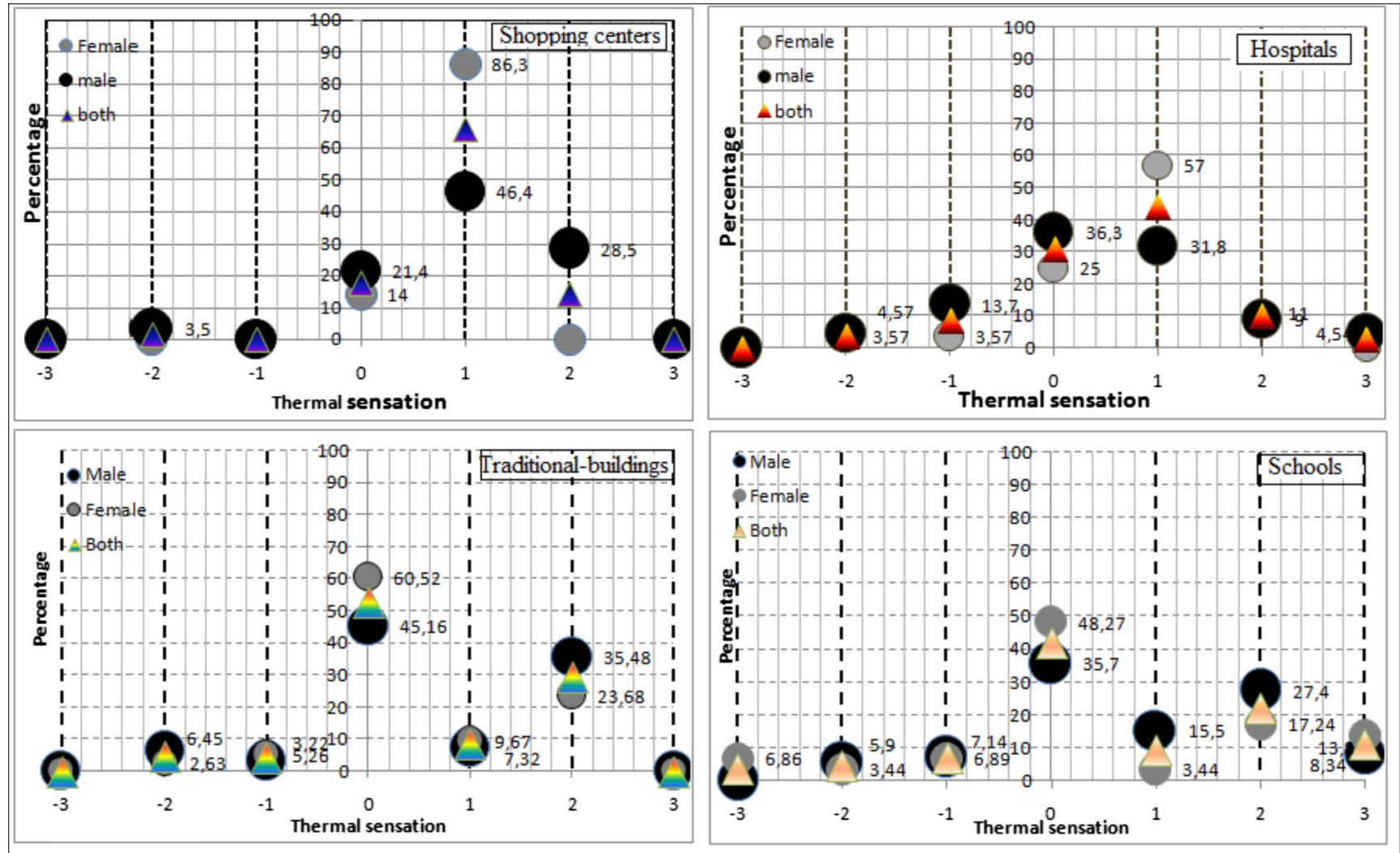

Fig. 1. The frequency distribution of thermal sensations of all the different studied places.

port of the country. It is the second largest bay in the world after Rio de Janeiro. 25 districts constitute the Urban Commune of Antsiranana which extends over $47 \mathrm{~km}^{2}$. The town is bounded to the north by the coves of the Dordogne and Melville, to the south by the plateau of Antanamitarana, to the east by the bay of the French and to the west by the deltaic plain of Antomboko and the plateau of Cape Diego. Detailed characteristics of the study area are given in Table 1.

Average rainfall of $12.4 \mathrm{~mm}$ makes the month of June the driest one, while in January rainfall is the highest in the year, with an average of $204.9 \mathrm{~mm}$.

\subsection{Experimental campaign and measurements instruments}

In this work, the primary objective was to propose a database on thermal comfort in natural ventilation in order to improve indoor air, mainly in schools, traditional buildings, hospitals, and shopping centers in the largest island of the Indian Ocean. A total of 22 students were selected and trained to conduct the survey. The main research methods included a survey questionnaire about thermal comfort, the interviews for patients who could neither read or well write, and measurement of some physical parameters. 


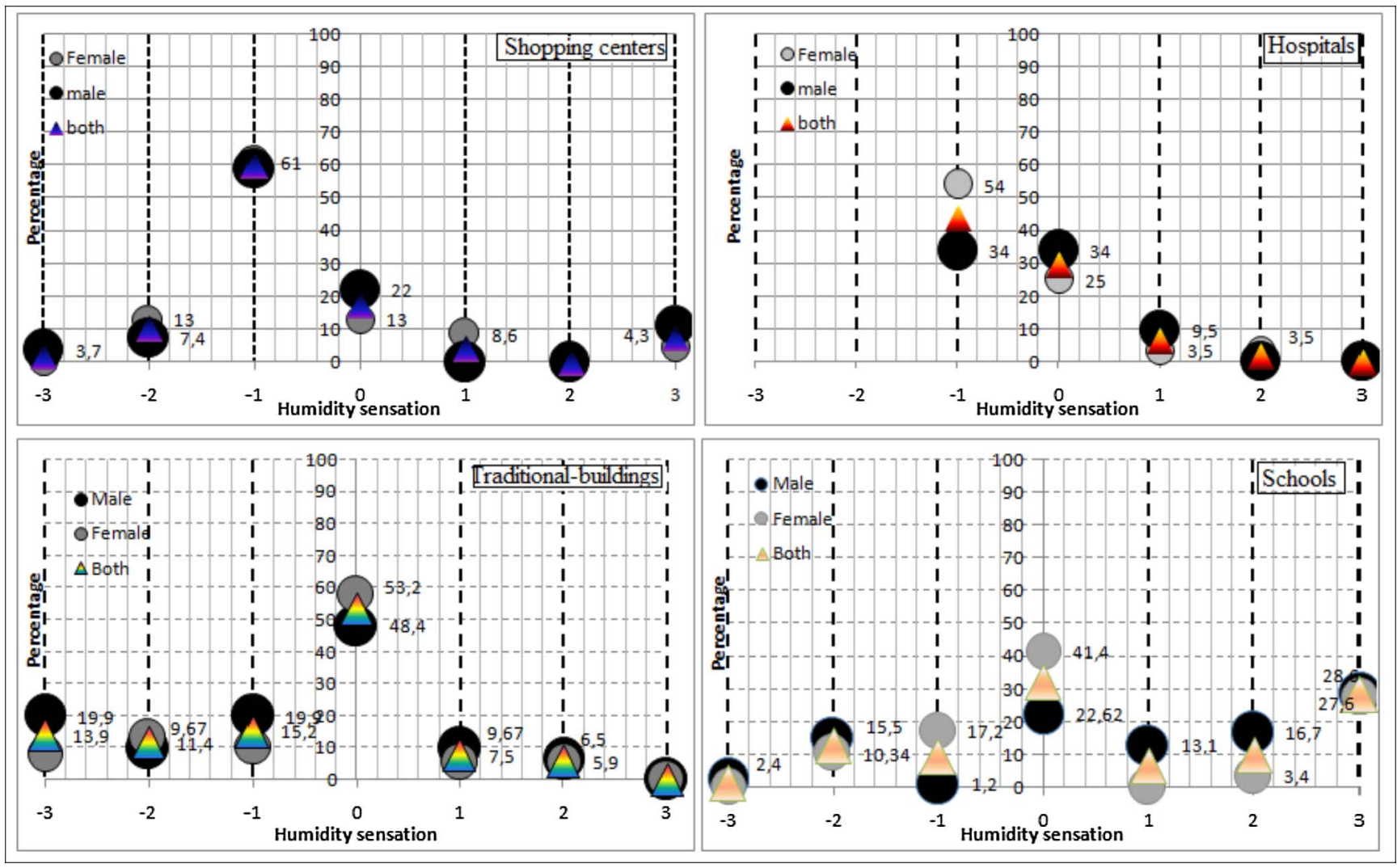

Fig. 2. The frequency distribution of humidity of all the different studied places.

An experimental campaign was carried out in 5 big hospitals, 50 small and big shopping centers, 67 traditional habitats and 25 private and public schools (elementary and high schools); located in 25 districts of the urban commune of Antsiranana. In total, 1092 people were investigated, with 250 interviews and 842 written responses (questionnaires).

The sample sex ratio was essentially $1: 1$, with 511 males and 581 females being investigated, in 45 sick rooms, 50 shopping rooms, 67 traditional habitats, and 30 classrooms.

Most of the selected hospitals were less old than 50 years. The hospitals were built using local materials such as concrete block and compressed stabilized earth block and also import materials (sliding glass, marble ...). The hospital plans had different geometric shapes and very beautiful architectures, that attracted the visions of the visitors and road users.

The shopping centers were in the great majority of cases located in the city center, and near to big crossroads. Their main wall façades were for the most part covered with clear glass, which allowed passers to admire the goods at tens meters (see Fig. 2d).

Most of the selected traditional habitats were older than 70 years; traditional houses were built using local materials, such as dry bamboo, red earth, straw leaf, enamelled iron, and sometimes using provisional materials. Most of these buildings were built around a century ago. Their heights varied between 1.9 and $4.5 \mathrm{~m}$. Most of these buildings had squared or rectangular plan, and their roof were formed of dry straw leaves, with more than $5 \mathrm{~cm}$ of thickness, a slope $45^{\circ} \mathrm{C}$, and sometimes covered with old rusted metal sheets (Fig. 2). They were mostly located in the peripheral quarters of the town and often grouped near the main road. Some of these habitats included sheet fences and earth brick around them. Other habitats were opened to the public, which facilitated the lighting of the indoor by the sunlight during the day. These buildings had small verandas on the main façade, that are used for rest and protection against sun and rain. The height or the length of most of the doors were less than $1.77 \mathrm{~m}$.
The schools were mostly located in densely populated neighborhoods and close to roads. Most of these establishments were built between 10 and 150 years ago, with plastered and painted wall and, sometimes, with earth brick. All these schools were protected and surrounded by large barriers and walls, that prevented students from coming home during study break. During this study, only naturally ventilated conditions were investigated. The study was conducted during the periods reported in Table 2. A detailed description and pictures of the investigated buildings are reported in [45].

The maximum, minimum, and mean air temperature, relative humidity and air speed were measured by a probe thermometer, thermohygrometer and anemometer. The mean radiant temperature $\left(\mathrm{T}_{\mathrm{r}}\right)$ was estimated using the following regression model as function of the measured air temperature $\left(\mathrm{T}_{\mathrm{a}}\right)$ proposed by Djongyang and Tchinda [46]. All these four parameters allow to characterize the studied physical indoor environments [47]. The sensitive infrared thermometer was used to measure the temperature inside the walls. The characteristics of the instruments are given in Table 3.

The infrared thermometer, allows to detect the maximum, minimum, and mean temperature. Some of the specific characteristics of the infrared thermometer are the specially clear laser point, a wide temperature range, and an adjustable emissivity (depending on the material). Measurements were taken every $5 \mathrm{~min}$ at a height of $1.5 \mathrm{~m}$ from the ground level, in strict accordance with the prescriptions of the ASHRAE 55 [47] and ISO 7730 [48].

\subsection{Survey questionnaire}

The subjective approach was necessary in this study. The questionnaires allowed to receive the subjective answers of patients (hospitals), customers (shopping centers), students (schools), and villagers (traditional buildings). It was carried out in parallel with the testing of the environmental variables. The opinions and feelings of individuals were obtained by a careful analysis of these questionnaires, developed 


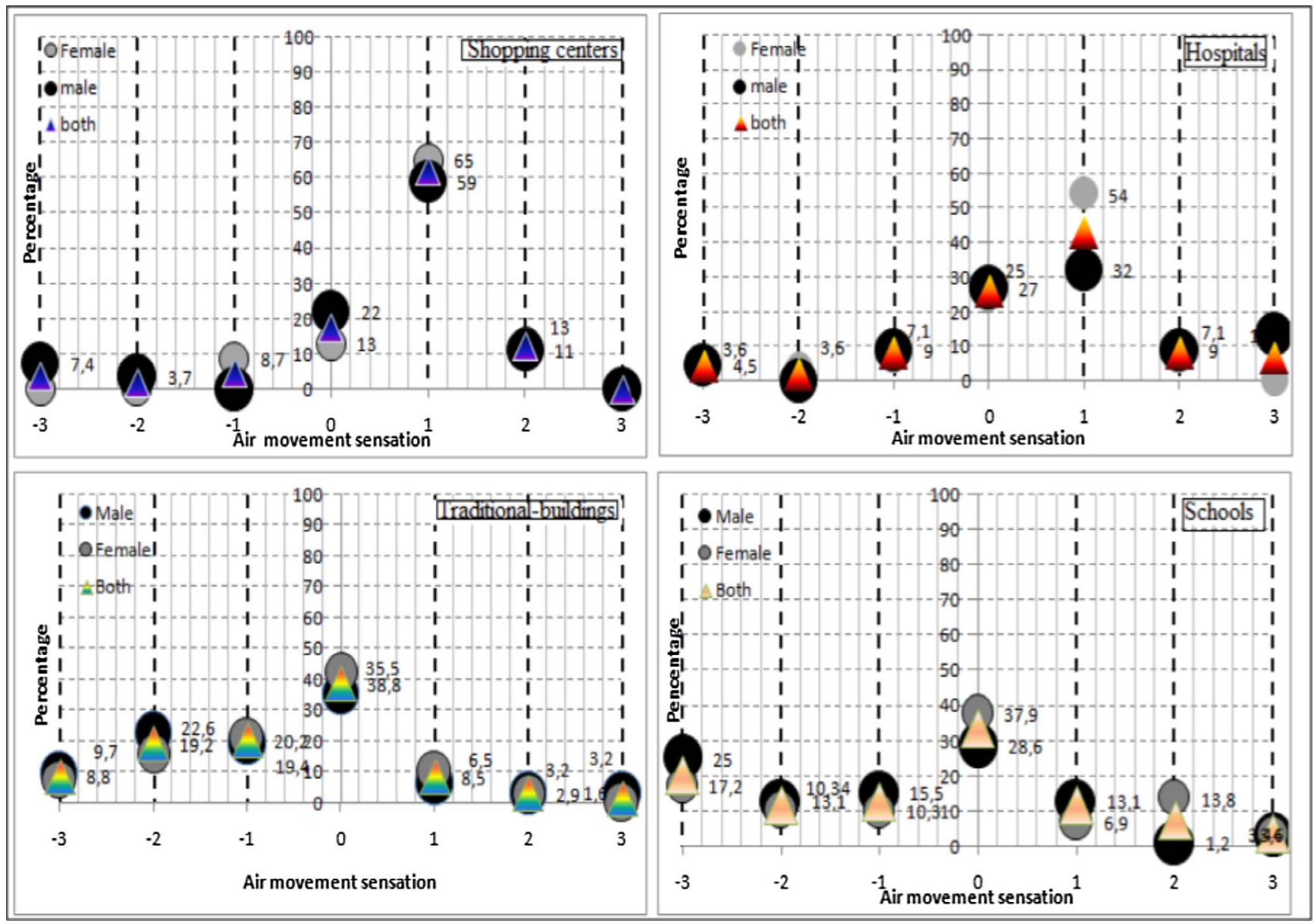

Fig. 3. The frequency distribution of air movement sensation of all the different studied places.

in previous works [6-9]. At total of 842 questionnaires were collected during both seasons: 1 customer for each of the 50 shopping center, 20 patients for each of the 5 hospitals, 1 person for each of the 67 traditional habitats and 25 students for each of the 25 schools. To encourage some patients who could neither read no write to participate in the study, oral hearing were collected. A total of 250 interviews, 198 in hospitals and 52 in shopping centers. The main contents of the survey questionnaire are summarised in the following paragraphs.

\subsubsection{Background information}

Questionnaires were written in French and Malgasy language, which are the country official languages. The language preferences of the occupants were considered while distributing questionnaires. The questionnaire is subdivided into three parts:

- Part 1: personal data (age, sex, gender, height, weight, and time period).

- Part 2: Thermal aspects are investigated such as: judgement about tolerability of thermal environment, air movement, temperature difference between head and ankle, activity performed in the last period, etc.

- Part 3: Personal microclimate control.

\subsubsection{Characteristics of the voters}

The surveys in the hospitals were very difficult and discouraging. More than $59 \%$ of people meet in hospital refused to participate at this study; the raison was mainly concerned about their health. The questionnaires were given randomly, without any physical constraint. The school inhabitants were younger and more capable of answering the questionnaires.
The height of the voters varied between $1.41 \mathrm{~m}$ and $1.89 \mathrm{~m}$ in all the studied places. Their weights ranged between 33 and $95 \mathrm{~kg}$. Their activities varied according to seasons. Meanwhile, the activities were intense in the traditional habitats compared to the three other studied places. Some characteristics of the voters are reported in Table 4.

\subsubsection{Clothing insulation effect}

Nowadays, clothing insulation can only be estimated by using thermal manikin. Indeed, in any comfort field survey, clothing insulation is always the most difficult to detect [49]. In ASHRAE database, for example, all clothing insulatuion estimations of the field surveys were converted using ASHRAE 55-1992 clo estimation method. All the other methods were almost similarly [49-55]. In this study, ASHRAE 552004, has been adopted as clo estimation method.

\subsubsection{Thermal comfort field survey}

The opinions of voters were obtained from analysis of questionnaires and interview responses. The thermal, humidity and air movement sensations were adopted according to American Society of Heating Refrigerating, and Air-Conditioning Engineers (ASHRAE) scale. Thermal satisfaction, preference and comfort were also estimated. The different used scales are detailed in Table 5 as in [47].

\section{Results}

In this research the 842 questionnaires and 250 interviews were collected during the two studied seasons, $57.2 \%$ in schools, $27.3 \%$ in hospitals, $9.4 \%$ in shopping centers, and $6.2 \%$ in traditional buildings. Statistics of the subjects of residential occupants and personal thermal variables from questionnaires are reported in Table 4. The majority of 


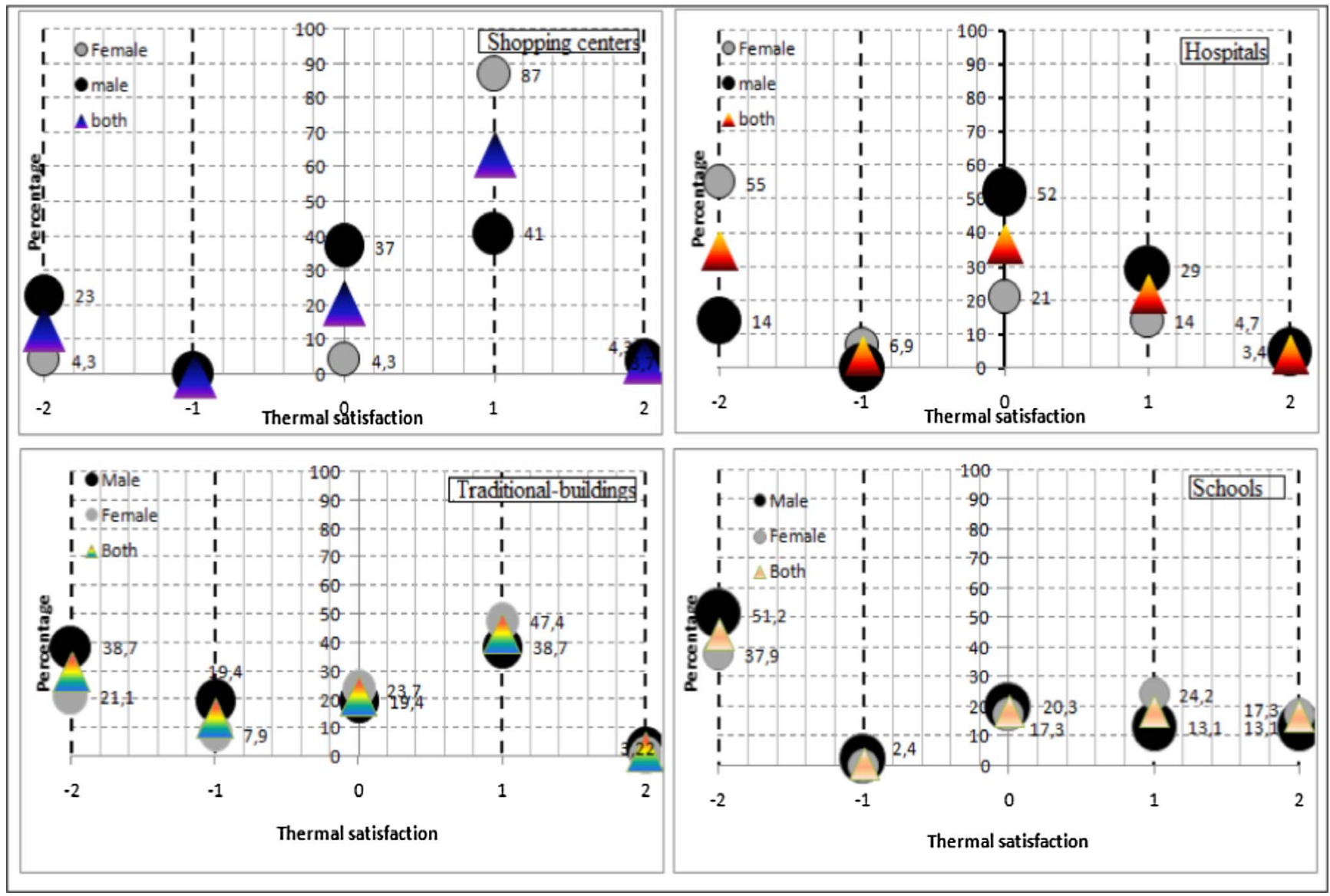

Fig. 4. The frequency distribution of thermal satisfaction of all the different studied places.

voters were women (53.2\%), the average age was 33 in all the analysed places, and the average clothing insulation was 0.92 clo in traditional buildings and shoppings, and 0.85 clo in schools and hospitals.

\subsection{Analysis of the measured indoor air data}

The air temperature ranged from a minimum of $20.49{ }^{\circ} \mathrm{C}$ to a maximum of $32.51{ }^{\circ} \mathrm{C}$, while the average was $26.32{ }^{\circ} \mathrm{C}$ and the standard deviation was 2.67. The fixed relative humidity values ranged from a minimum of $37.57 \%$ to a maximum of $73.50 \%$, while the average was $52.23 \%$ and the standard deviation was 10.96. Finally, the fixed wind speed ranged from a minimum of $0 \mathrm{~m} / \mathrm{s}$ to a maximum of $1.09 \mathrm{~m} / \mathrm{s}$, while the average was $0.417 \mathrm{~m} / \mathrm{s}$ and the standard deviation was 0.28 .

\subsection{Analysis of the subjective questionnaire}

\subsubsection{Thermal humidity and air movement sensations}

Fig. 1 shows the distribution of the subjective answers of thermal sensation in the different studied places during both seasons. In shopping centers, the $17.7 \%$ of the customers voted "neutral", the $66.1 \%$ voted "slightly warm" and the $14.3 \%$ voted "warm". Only $1.7 \%$ of custumers voted "cool environment". In hospitals, most patients (44.1\%) found their environment as "slightly warm", with regard to air temperature. The $31.0 \%$ of patients voted "neutral", and only the $2.7 \%$ found the environment "hot" during this period. In addition, in traditional buildings, the $52.8 \%$ of inhabitants voted "neutral environment", while the $29.6 \%$ and the $4.6 \%$ of people voted "warm" and "cool", respectively. Finally, in schools, most students $(42.0 \%)$ found their classrooms "neutral", the $22.3 \%$ of students voted "warm environment", and only, the $4.7 \%$ of schoolers voted "cool temperature". In all the studied places, during both seasons, no people voted "cold environment" as thermal sensation.

In Fig. 2, it appears that during both seasons, in the shopping centers, the $60.0 \%$ of custumers voted "slightly humid" as humidity sensation, while the $17.5 \%$ and the $10.2 \%$, of customers voted "neutral" and "dry", respectively. Only $4.3 \%$, of voters found "slightly humid environment". In hospitals, most patients (44.0\%) found their environment as "slightly dry", 29.5\% "neutral", 9.7\% "dry" and $1.75 \%$ "humid", as humidity sensation. On the other hand, in traditional buildings, the $53.2 \%$ of occupants voted "neutral environment", while the 13.9 and $5.9 \%$ of inhabitants voted "too dry" and "humid", respectively. Finally, in schools, the $32.0 \%$ of students voted "neutral environment", the 12.9 "dry" and the $10.0 \%$ "humid", while the remaining $28.1 \%$ voted "too humid" during both seasons. In all the studied places, most of the people voted "Neutral", as humidity sensation, while, the voters' minority, found "too humid environment".

Fig. 3 shows the frequency distribution of air movement sensation between the different studied places. In shopping centers, it was noticed that most of the customers (62.0\%) voted "slightly breeze environment" as air movement sensation, while the $17.5 \%$ of voters opted for "just right environment". Only the $3.7 \%$, voted "no wind" during both seasons. In hospitals, the $43.0 \%$ and the $26.0 \%$ of patients elected "slightly breezy" and "just right", respectively, as air movement sensation. The remaining $12.2 \%$ voted for "too breezy" and "no wind", with a repartition of $8.1 \%$ and $4.1 \%$, respectively. In addition, in traditional buildings, the $38.8 \%$ of occupants voted "just right air movement", while only $8.8 \%$ of inhabitants voted "no wind". Finally, in schools, the $33.4 \%$ of schoolers voted "slightly breeze", the $7.5 \%$ "too breezy" and the $20.2 \%$ "no wind". In each studied place, the minority of people voted "much too breezy", as air movement sensation during both seasons. 


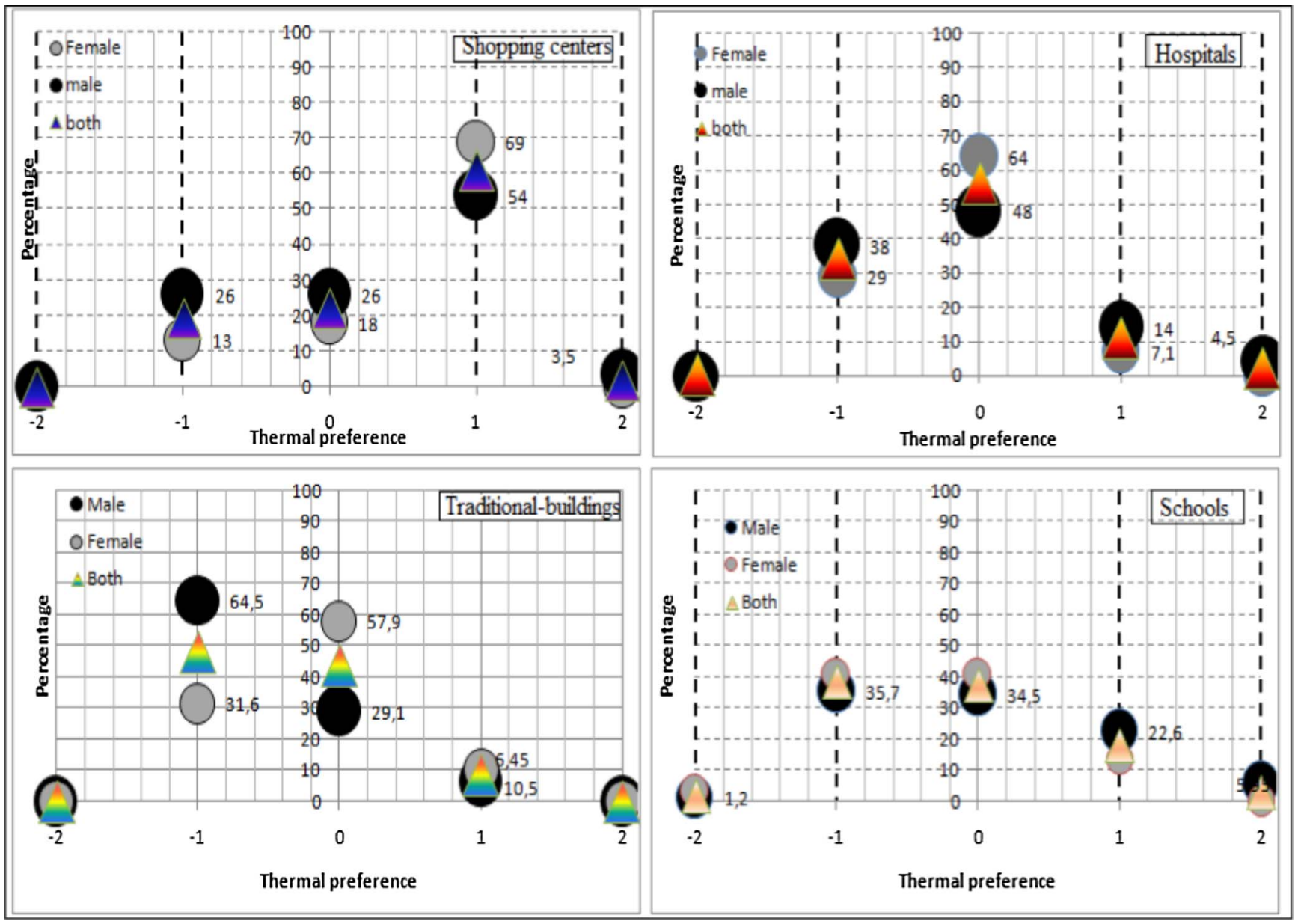

Fig. 5. The frequency distribution of thermal preference of all the different studied places.

\subsubsection{Thermal comfort, thermal preference, and thermal satisfaction}

The distribution of the subjective answers of thermal satisfaction is shown in Fig. 4. In the shopping centers the $64.2 \%$ of customers voted "slighly satisfied" as thermal satisfaction, while the remaining (35.8\%) voted for "satisfied", "dissatisfied" and "very satisfied", with a repartition of $21.0 \%, 13.6 \%$ and $4.0 \%$, respectively. In hospitals, it is important to notice that the $37.0 \%$ of patients selected "slighly satisfied", the $35.1 \%$ voted "dissatisfied" and only $3.5 \%$ of patients voted "satisfied". On the other hand, in traditional buildings, the most of inhabitants (43.1\%) voted "slighly satisfied", however, while the $21.5 \%$ of occupants voted "satisfied environment", the $29.9 \%$ of inhabitants were voting "dissatisfied environment". Finally, in schools, most of the students (44.6\%) voted "dissatisfied" as thermal satisfaction, the $17.2 \%$ of schoolers selected "very satisfied" area and only the $1.2 \%$ of students voted "slighly dissatisfied" during both seasons. Considering all the studied places, it was important to notice that the most of voters were "slighly satisfied" of their thermal environment.

In Fig. 5, it appears that during both seasons in the shopping centers most of the customers (61.0\%) preferred "slighly warmer", while the remaining (39.0\%), voted for "no change" and "slighly cooler", with a repartition of $22.0 \%$ and $17.0 \%$, respectively. In hospitals, the $56.0 \%$ and the $34 \%$ of patients wanted "no change" and "slighly cooler", during both seasons. In addition, in traditional buildings, the majority of inhabitants (48.2\%) wanted "slighly cooler" environment, while only the $8.5 \%$ of occupants preferred "slighly warmer". Finally, in schools, the $38.5 \%$ of students preferred "no change", while the least $(2.3 \%)$ voted "cooler" environment. Considering all the studied place, it was important to notice that most of the inhabitants preferred "slighly cooler" as thermal preference.
Finally, in Fig. 6 it appears that, in the shopping centers, most of the customers $(83.0 \%)$ voted "comfortable environment", while the remaining (17.0\%) voted "uncomfortable". In hospitals, the $100 \%$ of patients voted "comfortable environment", "uncomfortable" and "very uncomfortable", with repartition of the $87.0 \%, 8.3 \%$, and $4.7 \%$, respectively. On the other hand, in traditional buildings, most of the occupants (69.6\%) voted "comfortable environment", while a minority (the $1.7 \%$ ) voted "very uncomfortable environment". In schools, while the $57.3 \%$ of schoolers voted "comfortable environment", the $19.4 \%$ of students were voting "uncomfortable". Only some students $(0.56 \%)$, voted "very uncomfortable environment" during the studied period. In each studied place it was noticed that most of the inhabitants voted "comfortable environment".

\subsection{Analysis of significant dependency of thermal preference on thermal sensation}

Fig. 7 shows the linear regression analysis of thermal preference (TP) on thermal sensation (TS) related to season for gender. Many significant correlations $\left(R^{2}=0.964, \quad R^{2}=0.88, \quad R^{2}=0.61\right.$ and $\mathrm{R}^{2}=0.58$ ) were associated to several linear equations during both seasons:

$T P(\text { female })^{*}=-1.5(T S)+0.833, \quad R^{2}=0.964$, in shopping centers

$T P(\text { male })^{*}=-1(T S)+0.666, \quad R^{2}=0.428$, in shopping centers

$T P(\text { male })^{*}=T P(\text { female })^{*}=-0.5(T S)-0.285, \quad R^{2}=0.612$ in hospitals 


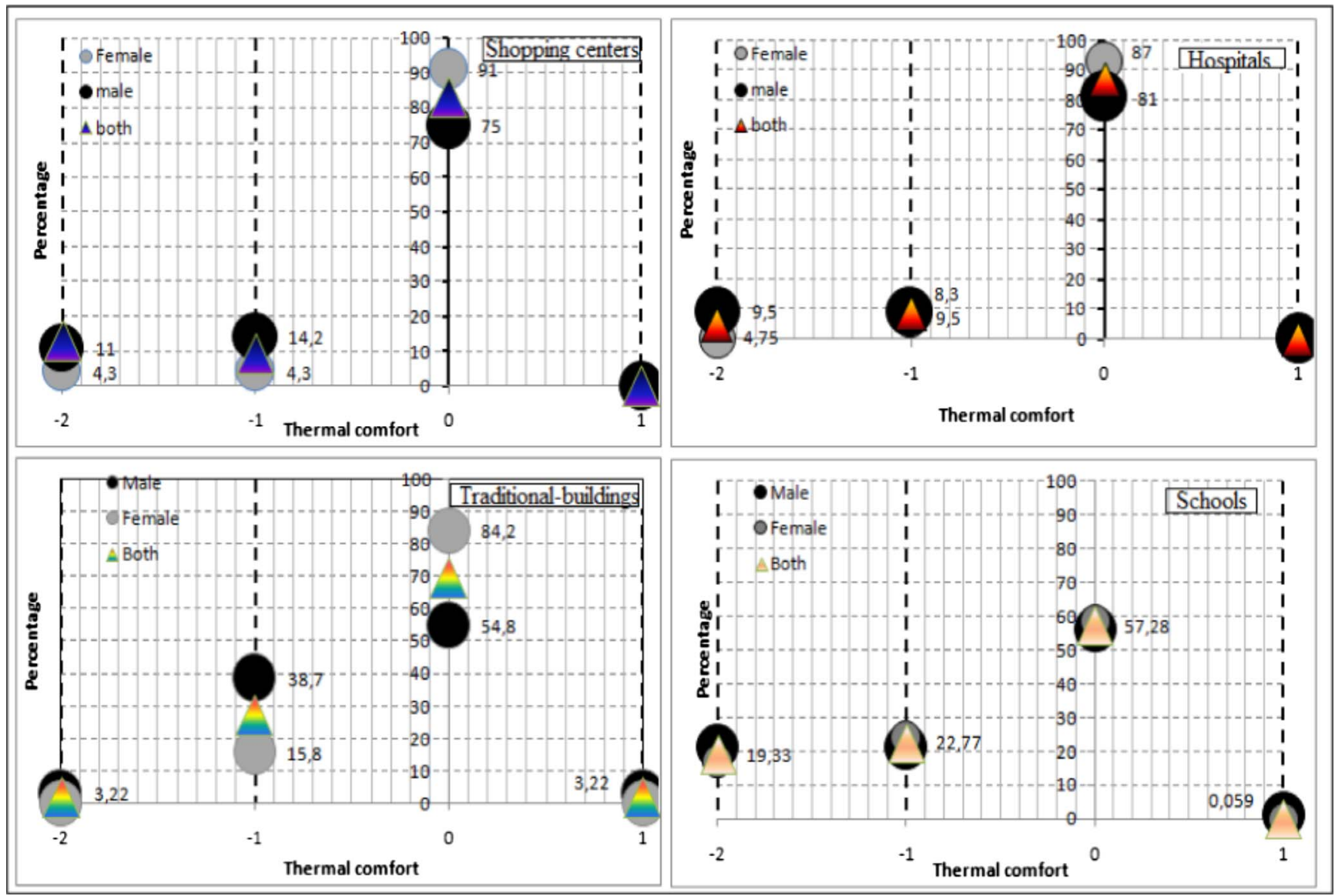

Fig. 6. The frequency distribution of thermal comfort of all the different studied places.

$T P(\text { female })^{*}=-1(T S)-0.4, \quad R^{2}=0.892$ in traditional buildings

$T P(\text { male })^{*}=-0.8(T S)-0.6, \quad R^{2}=0.888$, in traditional buildings

$T P(\text { female })^{*}=-0.178(T S)-0.857, \quad R^{2}=0.100$, in schools

$T P(\text { male })^{*}=-0.54(T S)+0.438, \quad R^{2}=0.583$, in schools

As axpected, slopes are negative; this means that thermal sensation does not evolve in the same direction as thermal preference. Globally, for neutral environment (TS $=0$ ), in shopping centers and schools, the males preferred "slightly warmer", while in hospitals and traditional buildings, the inhabitants wanted "slightly cooler environment". Thermal sensation associated with thermal preference equal zero ("no change") was "slightly warm" in both seasons. A similar work carried out by Eduardo et al. [55] showed that thermal sensation associated with thermal preference $=0$ ("nochange") was "slightly warm" in all seasons. The next subsection analyzed the thermal environment condition with Statistical software.

\subsection{Analysis of hourly statistical data}

The significance level allows to characterize the indoor environment's action on behaviour of occupant.

In Fig. 8a, are showed the similitude between the hospitals and shopping centers during the dry and rainy seasons. From this figure we can observe that during the period of strong activity (08:00-17:00), there is no a clear difference between voters' behaviour in both studied places, with a significance level clearly over 0.05 and, consequenly, indoor environments can be considered to reach the same behaviour. However, it can seem that there is a clear, greater tendency to reach a similar behaviour in hospitals than in shopping centers, because the significance level is slightly weak in hospitals.
From this difference in internal behaviour of indoor environments and from the initial ANOVA study, it can be concluded that the voters are feeling more comfortable in hospitals than in shopping centers.

Fig. 8b, represents the same comparison between traditional buildings and schools. From this figure, it can be concluded that only between 9:00 and 10:00, in traditional buildings, there is a clear difference in indoor environments behaviour (significance level below 0.05). During the remaining time, there is no significant statistical difference between the ambiences, despite this, it can be observed that in traditional buildings there is a certain higher similitude in indoor environments than schools, because significance level in traditional buildings is higher than schools.

\subsection{Analysis parametrics and interactions of environmental thermal and personal parameters}

In Fig. 9 is reported the effects of varying air temperature, clothing, and metabolism on the thermal satisfaction of occupants in studied places during both seasons. It is noticed that the satisfaction zone enormously varies as function of air temperature. The satisfaction zone is the most significant in traditional buildings, because at this time, more than $90 \%$ of voters are satisfied of environment. Metabolism and clothing are two personal parameters difficult to estimate. Metabolism is related to heat generation in the human body. As the metabolism of an occupant increases, the heat generation rate of his/her body increases, leading to a warmness sensation. This figure shows that metabolism has a major effect on an occupant's thermal sensitivity satisfaction when compared to clothing. However the effect of clothing is more dominate for lower clo values.

Fig. 10 shows the comfort zone area as a function of temperature, relative humidity and air speed. This figure indicates that the comfort 

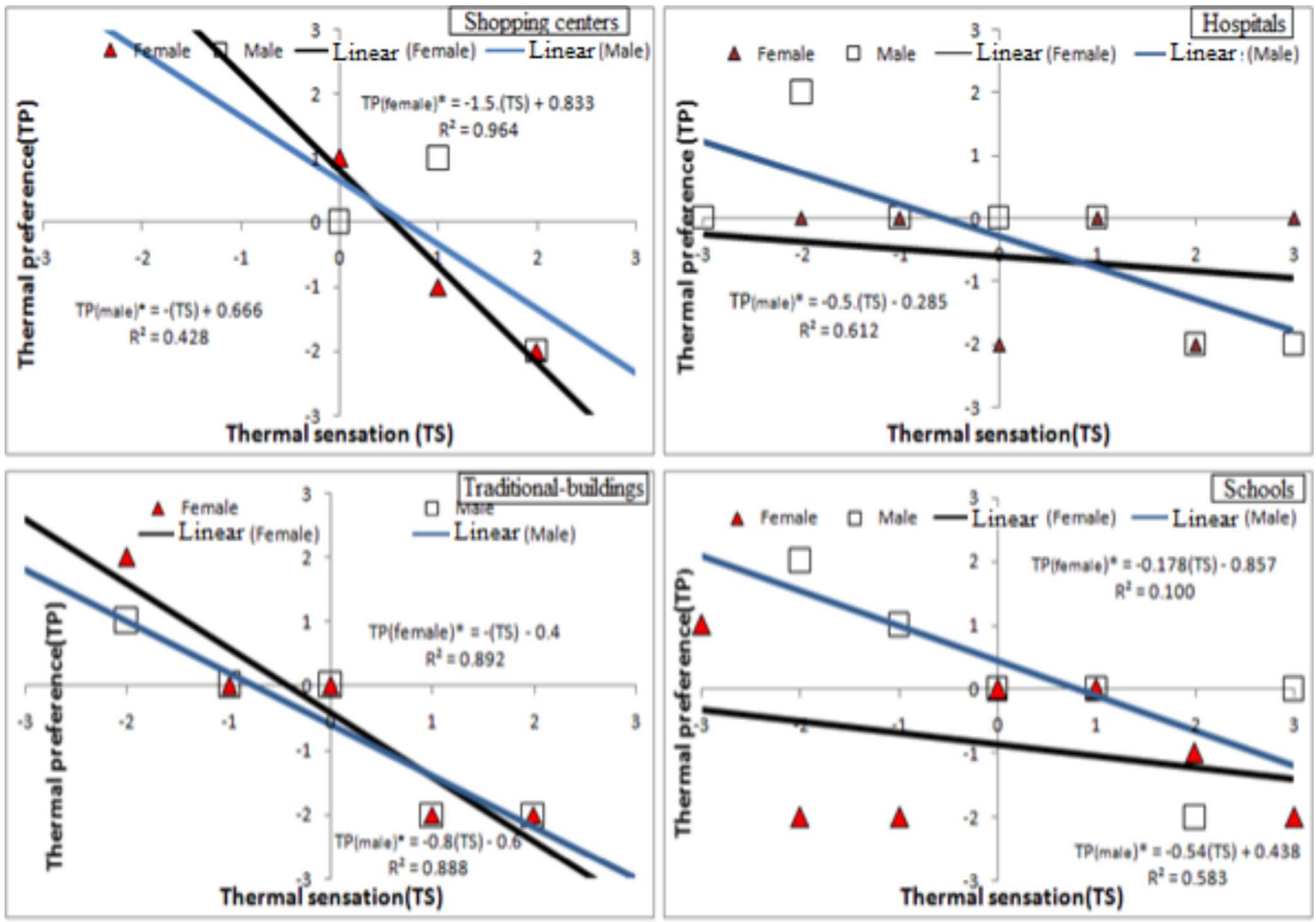

Fig. 7. Linear regression analysis of thermal preference (TP) versus thermal sensation (TS).

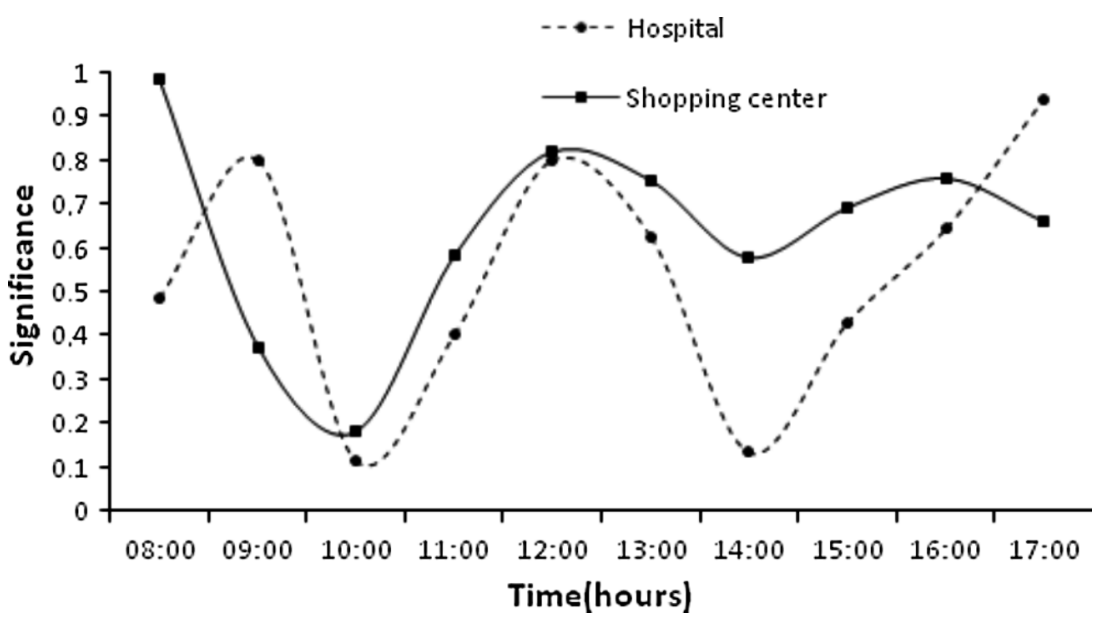

Fig. 8a. Comparison of indoor air behaviour in hospitals and shopping centers during both seasons.

zone is very sensitive to air speed. An interesting extremely high sensitivity is noticed when air speed is a round $0.5 \mathrm{~m} / \mathrm{s}$. With air temperature in the $22.9-27.2{ }^{\circ} \mathrm{C}$ range, relative humidity from 45.2 to $70.5 \%$, and air speed from 0.15 to $0.45 \mathrm{~m} / \mathrm{s}$, at least the $80 \%$ of voters found their environment comfortable in all the studied places during the two seasons.

\section{Discussion}

\subsection{Global analysis of subjective responses}

In a recent study carried out in Cameroon, results confirmed that the comfort temperature ranged between $23^{\circ} \mathrm{C}$ and $28^{\circ} \mathrm{C}$, whereas humidity ranged between $48 \%$ and $74 \%$ and air speed was about $0.49 \mathrm{~m} / \mathrm{s}$ [44]. Several researches considered by ASHRAE [47], found that the comfort temperature is between $23{ }^{\circ} \mathrm{C}$ and $26^{\circ} \mathrm{C}$, whereas humidity is between $30 \%$ and $60 \%$. In this study, the air temperature was between 22.9 and $27.2{ }^{\circ} \mathrm{C}$, relative humidity from 45.2 to $70.5 \%$, associated with 


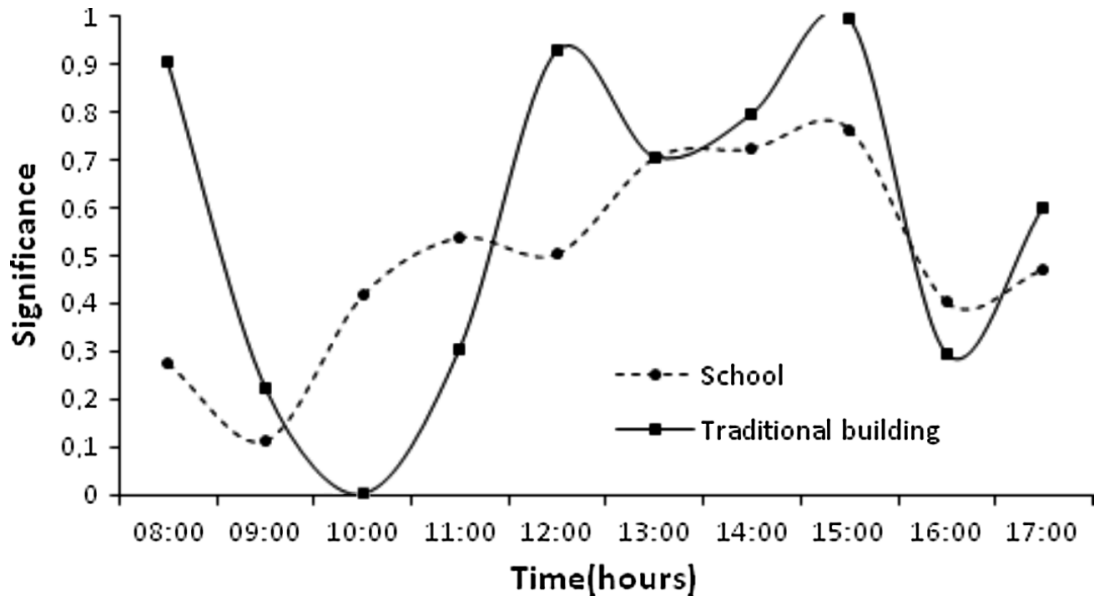

Fig. 8b. Comparison of indoor air behaviour in schools and traditional buildings during both seasons.
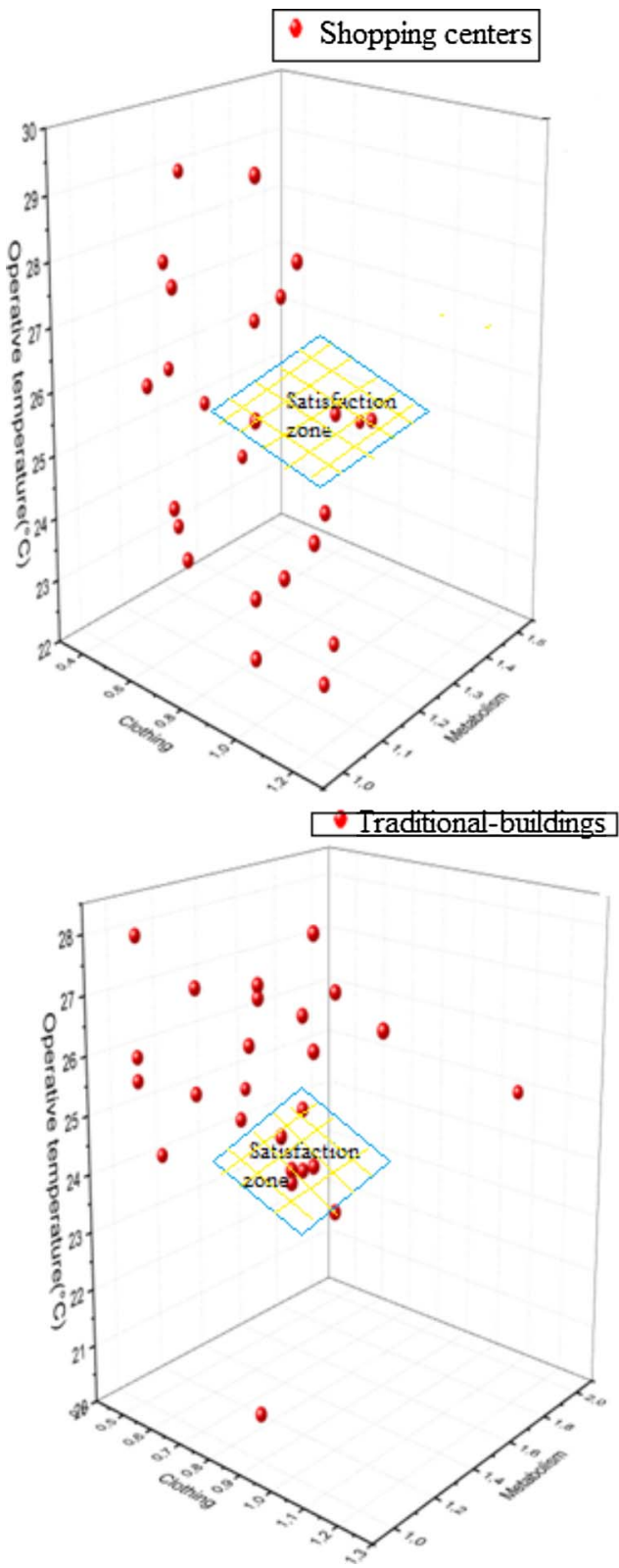

Fig. 9. Satisfaction zone in all the different studied places. 

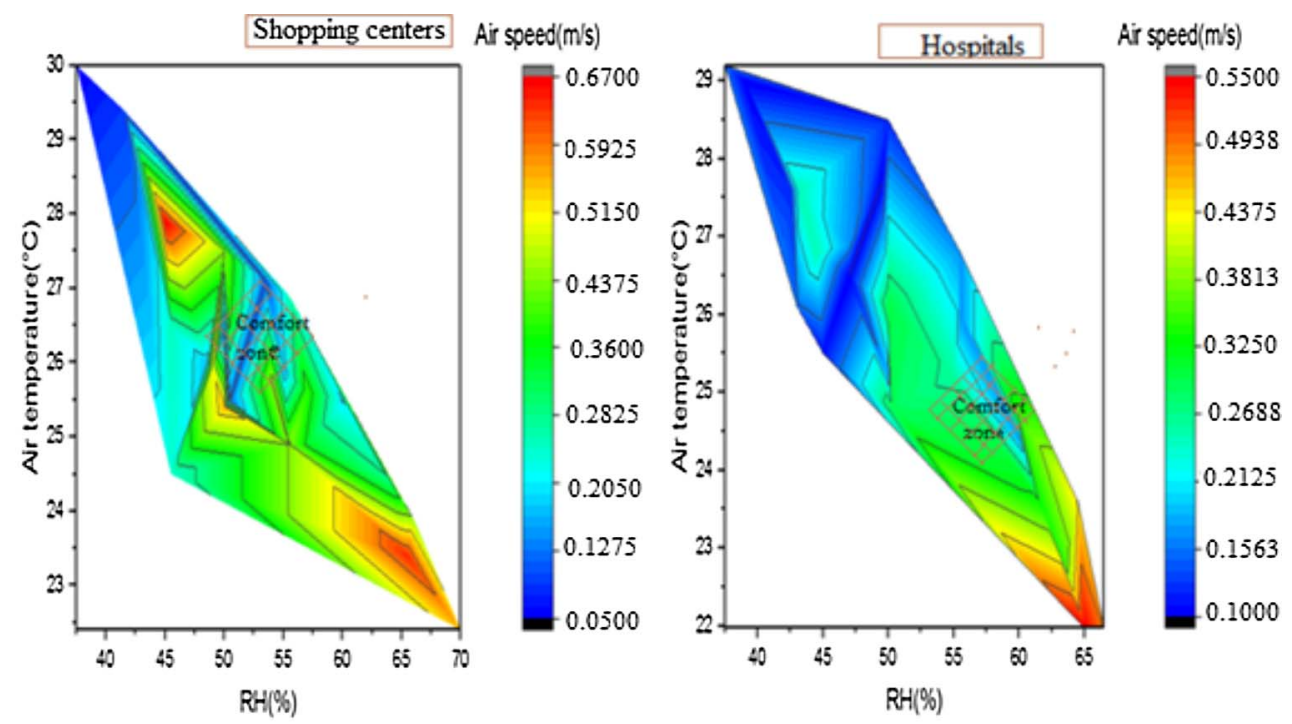

Fig. 10. Thermal comfort zone in all the different studied places.
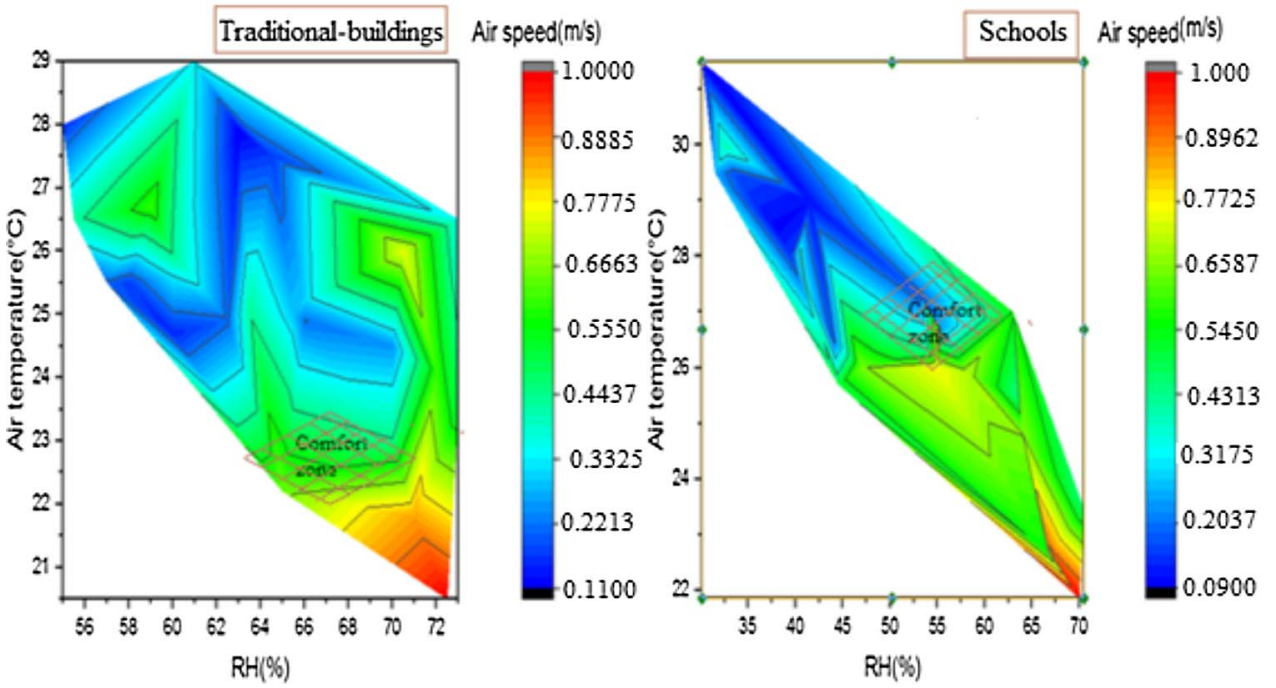

air speed from 0.15 to $0.45 \mathrm{~m} / \mathrm{s}$. All these above conclusions showed that comfort zone varied as function of the studied places. These results contribute to the advancement of the research because they propose a database on thermal comfort in an area that does not yet have a reliable construction standard. Figs. 1-3 presented the frequency distribution of the thermal, humidity, and air movement sensations of males and females. In these figures, it can be seen that there were no very great differences between males and females thermal sensations, humidity sensations, and air movement sensations in all the studied places. Indeed, the majority of them (about 37.2\%) thought the thermal environment neutral and a slightly humid (around of $32.8 \%$ ) and that the wind was slightly breezy (about 30.9\%). Nevertherless, for both sex, the smallest minority of voters (7.9\%), thought the environment was humid and cold with weak air speed. Many studies carried out in sub-Sahara Africa, in other type of climate found almost the same results [44,49]. Figs. 4-6 showed the frequency distribution of the thermal satisfaction levels, thermal preferences, and thermal comforts between males and females in all the studied places. During both seasons, in the hospitals, there were no obvious differences between the males and females in their thermal preferences and thermal comfort, since most of them thought the thermal environment was comfortable and preferred it to be no change, but their thermal satisfaction levels showed great differences. For the males, a great number of them (52.0\%), were satisfied of their thermal environment. However, the majority of females (around 55.0\%), felt dissatisfied. In the shopping centers, there were no obvious differences between males and females thermal satisfactions, thermal preferences, and thermal comfort, since most of them (64.2\%) thought the thermal environment slightly satisfying, and wanted it to be slightly warmer (around to $61.1 \%$ ). For both sexes, the $85.0 \%$ of customers considerated their environment as comfortable. In traditional buildings and schools, during both seasons, for males, there were no obvious differences in their satisfaction, preferences and thermal comfort, since about half of them (45.0\%) thought the thermal environment dissatisfying and preferred (around to 50.1\%) a slightly cooler, and while around to $55.2 \%$ found comfortable their environment. For females, most of the voters $(71.4 \%)$ found comfortable their environment. These obtained results are depending on the various activities related to the occupants. A significant value obtained above 0.05 explained the convergence of subjective responses of relative satisfaction, preference, and thermal comfort. In a tropical island in natural ventilation, Shilei and al. [4], using another method for field investigation in hotels and tourism places, found some similar results.

\subsection{Differential statistical analysis of sensations between ages}

In this sub-section, it was carried out the differential analysis between ages. Indeed, the voter's age as well as the sex, can strongly influence the sensations of occupants in their environment. This subsection, analyses the effect of age on the voters' choice. As in the majority of the most common applied used for the $t$-test, in this part, all the 


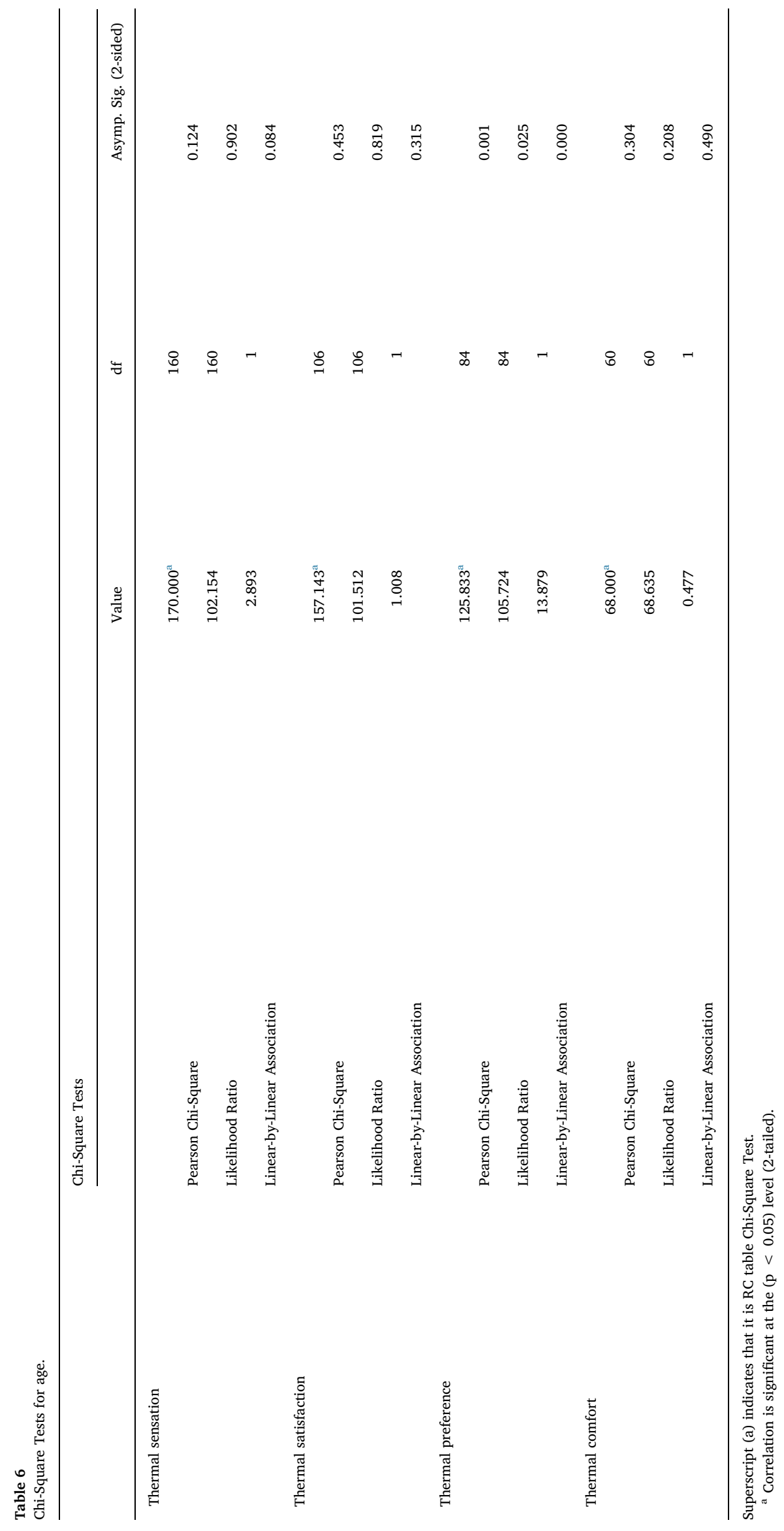


Table 7

Correlations between the thermal preference levels of young and old and the environmental variables.

\begin{tabular}{clll}
\hline & & $\begin{array}{l}\text { Thermal } \\
\text { preference of } \\
\text { young }\end{array}$ & $\begin{array}{l}\text { Thermal } \\
\text { preference of old }\end{array}$ \\
\hline Air temperature $\left({ }^{\circ} \mathrm{C}\right)$ & $\begin{array}{l}\text { Spearman } \\
\text { correlation }\end{array}$ & 0.1 & 0.022 \\
& $\begin{array}{l}\text { Sig. (2-tailed) } \\
\text { N }\end{array}$ & 0.033 & 0.009 \\
Relative humidity & $\begin{array}{l}\text { Spearman } \\
\text { correlation }\end{array}$ & $-0.067^{\mathrm{b}}$ & 224 \\
& $\begin{array}{l}\text { Sig. (2-tailed) } \\
\text { Air speed (m/s) }\end{array}$ & 0.057 & $-0.417^{\mathrm{b}}$ \\
& Spearman & 144 & 0.005 \\
& $\begin{array}{l}\text { correlation } \\
\text { Sig. (2-tailed) }\end{array}$ & $0.037^{\mathrm{a}}$ & 154 \\
& $\mathrm{~N}$ & 130 & 0.157 \\
\hline
\end{tabular}

${ }^{\mathrm{b}}$ Correlation is significant at the $(\mathrm{P}<0.01)$ level (2-tailed).

${ }^{\text {a }}$ Correlation is significant at the $(\mathrm{P}<0.05)$ level (2-tailed).

Table 8

Ordinal logistic regression between thermal preference and environmental variables for the young and old people.

\begin{tabular}{llllll}
\hline & \multicolumn{2}{l}{$\begin{array}{l}\text { Young' thermal preference } \\
\text { vote value }\end{array}$} & & \multicolumn{2}{l}{$\begin{array}{l}\text { Old' thermal preference vote } \\
\text { value }\end{array}$} \\
\cline { 2 - 3 } \cline { 5 - 6 } & Estimate & Sig. & & Estimate & Sig. \\
\hline $\begin{array}{l}\text { Air temperature } \\
\text { Relative humidity }\end{array}$ & $\begin{array}{l}0.567 \\
-\end{array}$ & 0.04 & & 0.759 & 0.008 \\
& & - & 0.230 & 0.013 \\
\hline
\end{tabular}

analysis were carried out with $95 \%$ of confidence level (CL) which was considered level of significance equal to $5 \%$. The thermal comfort differential analysis between age was carried out with Chi-Square method. This test is very important in this statistical study because it makes it easier to evaluate or compare two groups (or two measures) and easily take the best possible decision. With the SPSS software, the interval of significance can be freely selected; indeed, it is a quantitative estimate (called the p-value) of the probability that the observed differences are random. The voter's age were ranged in two categories; the young under 40 years and the old over 40 years. Results are showed in Table 6. All the statistical analyses were carried out by means of IBM SPSS 24.0 Statistical software. Table 6 shows the Chi-Square test results for young and old people with regard to the subjective responses differential analysis. It can be inferred from Table 6 that there was no obvious difference between the ages in the thermal sensations, thermal satisfaction, and thermal comfort votes $(\mathrm{P}>0.05)$, but the thermal preference votes showed obvious differences (as highlighted, the test is significant for $\mathrm{p}<0.05(5 \%)$; in this case, being the level of significance (p-value) equal to $0.001(0.001<0.05)$. A correlation analysis of the thermal preference levels between the ages was carried out to measure the impact of each environmental variable on the thermal preference (table 7). The analysis of table 7 showed that the age's thermal preference levels showed significant correlations with the air temperature $(\mathrm{P}<0.05)$ and relative humidity at old people $(\mathrm{P}<0.01)$. While the ages' thermal preference levels showed no significant correlations with air temperature, air speed and relative humidity $(\mathrm{P}>0.05)$. Ordinal logistic regression was used to reveal the relationship between thermal preference levels of people age and environmental variables, and Table 8 shows the results. In Table 8, it can be seen that significance level is less than 0.05 , so air temperature and relative humidity have significant impact on the thermal preference of occupants in all the studied places.

All the above results showed that some parameters such as air temperature and relative humidity, can together influence thermal preference of voters in the studied sites. Kameni et al. [54] in a previous research, found that in sub-Sahara Africa the wall construction materials have a significant action over indoor air quality.

\section{Conclusion}

The present statistical study of questionnaires provided the subjective answers with regard to thermal comfort of the occupants in some schools, hospitals, traditional buildings and shopping centers in Madagascar; they were located in 25 districts with different micro-climates of urban communes in Northern of Madagascar. Data analysis revealed that there were not very great differences between males and females in their thermal sensations, humidity sensations, and air movement sensations in the all the studied places. More than $70 \%$ of people voting "neutral" as thermal sensation preferre "slightly cooler environment". For males, a great number of them $(52.0 \%)$ were satisfied with their thermal environment. However, the majority of the females (around 55.0\%) felt dissatisfied. A preliminary ANOVA analysis under internal behaviour of indoor ambiences showed that the voters are feeling more comfortable in hospitals than shopping centers. On the other hand, it was observed that in traditional buildings there was a higher similitude in indoor environments than schools. These results can help the architects and severals disigners to adapt the materials and construction types in Indian Ocean buildings, aiming at improving thermal comfort and reducing energy consumption.

\section{Acknowledgment}

The authors acknowledge the Centre for International Cooperation and Development (CICOPS) Project for their support in this work.

\section{References}

[1] Khanal R, Lei CW. Solar chimney-a passive strategy for natural ventilation. Energy Build 2011;43:1811-9.

[2] Shi Long, Zhang Guomin, Cheng Xudong, Guo Yan, Wan Jinhui, Chew Michael Yit Lin. Developing an empirical model for roof solar chimney based on Experimental data from various test rigs. Build Environ 2016;110:115-28.

[3] Chan SC, Che-Ani AI, Nik Ibrahim NL. Passive designs in sustaining natura ventilation in school office buildings in Seremban, Malaysia. Int J Sust Built Environ 2013;2(2):172-82.

[4] Shilei Lu, Xia Hongwei, Wei Shasha, Fang Kun, Qi Yunfang. Analysis of the differences in thermal comfort between locals and tourists and genders in semi-open spaces under natural ventilation on a tropical island. Energy Build 2016;129:264-73.

[5] Buratti C, Ricciardi P, Vergoni M. HVAC systems testing and check: a simplified model to predict thermal comfort conditions in moderate environments. Appl Energy 2013;104:117-27.

[6] Buratti C, Ricciardi P. Adaptive analysis of thermal comfort in university classrooms: correlation between experimental data and mathematical models. Build Environ 2009;44:674-87.

[7] Ricciardi P, Ziletti A, Buratti C. Evaluation of thermal comfort in an historical Italian opera theatre by the calculation of the neutral comfort temperature. Build Environ 2016;102:116-27.

[8] Ricciardi P, Buratti C. Thermal comfort in the Fraschini theatre (Pavia, Italy): correlation between data from questionnaires, measurements, and mathematical model. Energy Build 2015;99:243-52.

[9] Ricciardi P, Buratti C. Thermal comfort in open plan offices in northern Italy: an adaptive approach. Build Environ 2012;56:314-20.

[10] Buratti C, Ricciardi P, Vergoni M. HVAC systems testing and check: a simplified model to predict thermal comfort conditions in moderate environments. Appl Energy 2013;104:117-27.

[11] Luo Xuan, PohLam Khee, Chen Yixing, hen Hong Tianz. Performance evaluation of an agent-based occupancy simulation model. Build Environ 2017;115:42-53.

[12] Yan Wu, Niu Jianlei. Numerical study of inter-building dispersion in residential Environments: prediction methods evaluation and infectious risk assessment. Build Environ 2017;115:199-214.

[13] Arrigoni Alessandro, Grillet Anne-ecile, Pelosato Renato, Dotelli Christopher Giovanni, Beckett TS, Woloszyn Monika, et al. Reduction of rammed earth's hygroscopic performance under stabilisation: an experimental investigation. Build Environ 2017;115:358-67.

[14] Hasan Mohammad H, Alsaleem Fadi, Rafaie Mostafa. Sensitivity study for the PMV thermal comfort model and the use of wear able devices biometric data for metabolic rate estimation. Build Environ 2016;110:173-83.

[15] Kobayashi Tomohiro, Sugita Kazuki, Umemiya Noriko, Kishimoto Takashi, 
Sandberg Mats. Numerical investigation and accuracy verification of indoor environment for an impinging jet ventilated room using Computational fluid dynamics. Build Environ 2017;115:251-68.

[16] Barbeito Inés, Zaragoz Sonia, Tarrío-Saavedra Javier, Naya Salvador. Assessing thermal comfort and energy efficiency in buildings by statistical quality control for auto correlated data. Appl Energy 2017;190:1-17.

[17] Nguyen Anh Tuan, Kumar Manoj, Reiter Sigrid. An adaptive thermal comfort model for hot humid South-East Asia. Build Environ 2012;56:291-300.

[18] Wagner A, Gossauer E, Moosman C, Gropp Th, Leonhart R. Thermal comfort and workplace occupant satisfaction-results of field studies in Germanlow energy office buildings. Energy Build 2007;39:758-69.

[19] Wagner A, Roberto L. Thermal comfort in buildings located in regions of hot and humid climate of Brazil. Energy Build 2005;1:23.

[20] Jin Hong, Li Xinxin, Kang Jian, Kong Zhe. An evaluation of the lighting environment in the public space of shopping centres. Build Environ 2017;115:228-35.

[21] Belleri A, Avantaggiato M. Ventilative cooling and shopping center's retrofit. RREHVA J 2016:21-5.

[22] Montella F. Sustainable design for retail buildings. In: PLEA 2008 - 25th conference on passive and low energy architecture, Dublin, 22nd to 24th October; 2008.

[23] Morgan Craig, de Dear Richard. Weather, clothing and thermal adaptation to indoor climate. Clim Res 2003;24:267-84.

[24] Azizpour Fatemeh, Moghimi Saeid, Lim Chinhaw, Mat Sohif, Zaharim Azami, Kamaruzzaman. Thermal comfort assessment in large scale hospital: case study in Malaysia. In: Recent researches in geography, geology, energy, environment and biomedicine; 2011. p. 171-4.

[25] Khodakarami Jamal, Nasrollahi Nazanin. Thermal comfort in hospitals - a literature review. Renew Sustain Energy Rev 2012;16:4071-7.

[26] Hwanga Ruey-Lung, Lin Tzu-Ping, Cheng Ming-Jen, Chien Jui-Hung. Patient thermal comfort requirement for hospital environments in Taiwan. Build Environ 2007;42:2980-7.

[27] Khodakarami Jamal, Knigh Ian. Thermal comfort requirements in Iranian hospitals. Proceedings of Clima Well Being Indoors 2007;3(7).

[28] Melhado MA, Hensen JLM, Loomans M. Literature review of staff thermal comfort and patient "Thermal Risks" in Operating Rooms. Kluwer Academic Publishers, p. 1-4.

[29] Patania F, Gagliano A, Nocera F, Galesi A. Thermal comfort in operating rooms: a case study. Environ Health Biomed 2007:105-15.

[30] Wu Jiayi. Slope flows and thermal comfort for hospital natural ventilation. Topic to obtain Master of Philosophy Department of MechanicalEngineering at The University of Hong Kong in July 2010; 2010.

[31] Smith RM, Rae A. Thermal comfort of patients in hospital ward areas. J Hyg (Lond) 1977 Feb;78(1):17-26.

[32] Liu Chunhua, Zhou Guang, Li Hongyuan. Analysis of thermal environment in a hospital operating room. Procedia Eng 2015;121:735-42.

[33] Nematchoua Modeste Kameni, Tchinda René, Ricciardi Paola. Thermal Comfort and Air Movement preference in some classrooms in Cameroun. Revue des Energies Renouvelables 2014;17:263-78.

[34] Teli Despoina, Jentsch Mark F, James Patrick AB, Bahaj AbuBakr S. Field study on thermal comfort in a UK primary school. In: Proceedings of 7thWindsor conference: the changing context of comfort in an unpredictable world Cumberland Lodge, Windsor, UK, 12-15 April 2012. London: Network for Comfort and Energy Use in Buildings, < http://nceub.org.uk $>$.

[35] Sullivan Patrick, Trujillo Allen. The importance of thermal comfort in the classroom. West Point, NY: United States Military Academy; 2015.

[36] Kamaruzzaman Khadijah, Samsul bin Azimin, Tazilan Mohd. Thermal comfort assessment of a classroom in tropical climate conditions. In: Recent advances in energy, environment and development. p. 87-91.

[37] Dili AS, Naseerb MA, ZachariaVarghese T. Thermal comfort study of Keral a traditional residential buildings based on questionnaire survey among occupants of traditional and modern buildings. Energy Build 2010;42:2139-50.

[38] Sharples S, Malama A. Thermal performance of traditional housing in the cool season in Zambia. Renew Energy 1996;8:190-3.

[39] Li J. The bioclimatic features of vernacular architecture in China. Renew Energy 1996;8:629-36.

[40] Malama A, Sharples S. Thermal performance of traditional and contemporary housing in the cool season of Zambia. Build Environ 1997;32:69-78.

[41] Vyas D. Traditional Indian architecture-the future solar buildings. In: International conferenceon passive and low energy cooling for the built environment, Santorini Greece; May 2005.

[42] Achyuthan A, Balagopal TSP. Green architecture-traditional and modern, Institution of Engineers (India). Architect Eng 2007;88:2-5.

[43] Edward S, Kurian D. Thermal performance of traditional buildings in Kerala. J Indian Inst Arch 2008:7-8.

[44] Nematchoua Modeste Kameni, Tchinda René, Orosa José A. Thermal comfort and energy consumption in modern versus traditional buildings in Cameroon: a questionnaire-based statistical study. Appl Energy 2014;114:687-99.

[45] Nematchoua Modeste Kameni, Ricciardi Paola, Buratti Cinzia. Adaptive approach of thermal comfort and correlation between experimental data and mathematical model in some schools and traditional buildings of Madagascar under natural ventilation. Build Environ 2017;1.

[46] Djongyang N, Tchinda R. An investigation into thermal comfort and residential thermal environment in an intertropical Sub-Saharan Africa Region: field study report during the harmattan season in Cameroon. Energy Convers Manage 2010;51(7):1391-7.

[47] ASHRAE Standard 55. Thermal environment conditions for human occupancy, Atlanta, Ga., USA; 2004

[48] UNI EN ISO 7730. Ergonomics of the thermal environment-analytical determination and interpretation of thermal comfort using calculation of the PMV and PPD indices and local thermal comfort criteria; 2006.

[49] Nematchoua Modeste Kameni, Tchinda René, Orosa José A. Adaptation and comparative study of thermal comfort in classrooms and buildings naturally ventilated in west tropical zones. Energy Build 2014;85:321-8.

[50] CIBSE. Environmental design, CIBSE Guide A, the chartered Institution of Building Services Engineers, London; 1999.

[51] McIntyre DA. Indoor climate. London: Applied Science Published Ltd.; 1980.

[52] Benignus VA. Handbook of neurotoxicology. New-York: Marcel Dekker; 1995. p. 1103.

[53] Nematchoua Modeste Kameni, Tchinda René, Orosa José A, Andreasi Wagner Augusto. Effect of wall construction materials over indoor air quality in humid and hot climate. J Build Eng 2015;3:16-23.

[54] Deb C, Ramachandraiah A. Evaluation of thermal comfort in a rail terminal location in India. Build Environ 2010;45:2571-80.

[55] Krüger Eduardo L, Tamura Cintia A, Peter Marcel Schweiker, Wagner Andreas. Short-and long-term acclimatization in outdoor spaces: exposure time, seasonal and heat wave adaptation effects. Build Environ 2017;116:17-29. 